\title{
The Project of a New Controlling System
}

\author{
Erika Fecková Škrabuláková'* , Elena Grešová', Jozef Svetlík² \\ 1 Institute of Control and Informatization of Production Processes, Faculty of Mining, Ecology, Process Control \\ and Geotechnologies, Technical University of Košice, Němcovej 3, 04200 Košice, Slovakia \\ 2 Department of Manufacturing Machinery, Faculty of Mechanical Engineering, Technical University of Košice, \\ Letná 9, 04200 Košice, Slovakia \\ * Corresponding author's e-mail: erika.feckova.skrabulakova@tuke.sk
}

\begin{abstract}
The main aim of this paper was to analyze the actual state of buying and selling cut-flowers in a chosen company. New controlling system was suggested for this company on the basis of collected and consequently separated, compiled and organized data. This system should provide the information on the anticipated development of purchase in the future. The motivation for creating the new system was given by the actual problems appearing due to not very clear and transparent way of flowers buying decision making. Especially considering the decisions about the amount and sorts of cut-flowers booked in advance. The new controlling system was designed in order to improve the current state of warehouse supply chain management. We believe that it would be useful in the process of planning, deciding, controlling and evaluation of orders exactness.
\end{abstract}

Keywords: controlling system, decision making, flowers buying, lean logistics, supply chain management

\section{INTRODUCTION}

Logistics represents a very important set of activities from the viewpoint of world economy development. Equally important is its role at the level of individual companies. Logistics ensures the optimal flow of information, services and goods [3]. The basic objective of logistics in supply chain management constitutes transporting and placing goods in a way that brings benefits from time, space, and ownership savings at minimal cost $[3,14]$.

Increasing the connectivity among companies leads to significant savings in financial and material resources, costs reduction, and what is the most important, to increase in profits and gaining competitive advantage. However, the risk of this system is an unexpected outage of the supply. This causes problems for companies, as the vast majority of them employ the system of maintaining a minimum stock level. Thus, a potential necessity of short term lending occurs in some cases.
Nowadays, due to the competition in the global environment [7], most of the companies are forced to make improvements in their supply chain management [5], in order to produce low cost, but high quality products that ensure satisfaction of both customers and suppliers [2] as well as fulfill the market requirements efficiently and dynamically [1] while respecting the increased environmental standards [6]. The essence of the supply chain management strategy is to find a balance between costs, efficiency and quality on the one hand, and chain vulnerability and dependence on the other [12]. It should be remembered that the supply chain management of large companies is different from that applied in small and medium-sized enterprises, whose resources are more limited [15]. That is the reason why this management type is much more important for them. Controlling focuses on those areas where the problems arise most frequently. It is one of the tools to ensure the achievement of business goals. A suitable system of planning, 
information and control providing the support of the organizational creativity within the management is implemented there, also bridging the gaps in the organizational structure. Thus, the contribution to the effective management of the business is gained. Controlling, as a tool for lean logistics can be applied, already in the research phase. However, it is likewise used in design (see e.g. [16]), production, process control (see e.g. [10]), supply (see e.g. [8]), in the sale and purchase, for example of the flowers.

We discuss the advantages of using controlling, inventory management and cost optimization by controlling approach in this work. The main aim of this paper is to propose a controlling system for the purchase of flowers and to propose statistical processing of the existing data so that the information and numerical values obtained can be applied to simplify the decision making process and the early recognition of the approaching critical periods in the state of cut flowers stock. In this work, the authors went into individual business and reacted to the needs of a particular concrete company from eastern Slovakia. We propose a new method for controlling the sellers of the given company based on the 1-year data. Hence, the proposed system is not a copy of some system that is employed in a similar company. Moreover, this study helps to bridge the gap between the theoretical work and actual practice. Its importance is underlined by the fact that the obtained results were given to the company representatives for implementation into the test phase.

\section{NEED OF THE STUDY}

The advantages of controlling can be found in various areas of business activity and can be assessed in several ways: planning, efficiency and management. The ideal ground for controlling is poor planning. Controlling encourages reconsidering one's actions just by comparing the expected and actual state [15]. The utilized planning and management system has a significant impact on business logistics. A traditional system is a system of pressure, where a failed sales strategy causes the accumulation of goods and its surplus in warehouses. Therefore, the pulling system is now increasingly used in the logistics operations process. The system requires permanent information about the market situation. The storage spaces can then serve exclusively for a temporary storage of goods.

The amount of demand is the value that an enterprise can only estimate on the basis of experience, market information, forecasts, and so on. The factors entering the sales process may vary - for example order cycle, shipping time, order preparation or total delivery time. The company has to find the optimal ratio between the storage costs and the cost of insufficient inventory keeping stocks high enough or risking the loss of profits if stocks are depleted.

The high degree of uncertainty associated with demand and the total time of stock replenishment means that managers are more focused on when to order and not on how much they need to order. The quantity ordered is important to the extent that the number of orders affects [11].

The key effort of companies is to increase the inventory turnover. If the enterprise has large inventory, increasing the inventory turnover brings an increase in profitability. Excessive efforts to increase the inventory turnover may paradoxically reduce the profitability of an enterprise. Therefore, all changes need to be done systemically, since everything is related. In every business that is trying to be competitive, the effort to optimize in all areas of its management must be discerned, and the inventory does not fade. The controlling approach can create an appropriate cost monitoring system, detect the cost management deficiencies and improve the ways to effectively reduce them. The controlling concept is based on a continuous comparison of the actual costs with the planned ones, detection of the deviations and their, monitoring of the effect of the deviations on the fulfillment of set objectives. This paper does not deal with some theoretical system control, which remains just on the model level. We focus on a specific company, the business subject of which includes the purchase and sale of the flowers. It is located in the east of Slovakia. The necessity of the controlling system design is particularly justified in the case of the corresponding company, which is one of the largest wholesalers of cut flowers and potted plants in Slovakia with annual turnover of about 1.5 million cut roses, 2.2 million carnations, 400 thousand tulips, 500 thousand chrysanthemums and about 85 thousand potted orchids.

The purchase of cut flowers was based only on the experience of the employee responsible for managing the warehouse stock in the surveyed 
company. For years, the company has been buying flowers from the Dutch stock market through Dutch floral companies. Increasing competition on the Slovak market has prompted the company to look for additional resources and, in particular, more cost-effective forms of purchasing goods. Therefore, the company has entered into contracts with other Dutch florist companies, offering newer items, higher standards of service, transportation, access to information on new trends, and helping to promote a domestic business in Slovakia. Establishing new contacts resulted in an increment in the company's turnover and profit (see Fig. 1), mainly after 2007 (branch office in Košice). The company noticed a significant reduction in profit in sales of cut flowers, especially in the Košice branch at the end of 2011. The sales of cut flowers account for up to $68 \%$ of the total annual turnover. The company's goal is to maintain this value or increase it to $75 \%$. In order to maintain a leading position in the Slovak market, it is necessary to keep track of the trends in Slovakia, around the world, on floral exchanges and thoroughly review the processes in the company itself, including the purchasing and selling economy as well as to monitor the performance of its employees. Consequently, the company's management came to the conclusion that it will be unavoidable to prepare a report on why this loss of profits has occurred and to propose an effective mechanism to eliminate similar cases in future.

\section{DATA AND METHODS OF THE RESEARCH}

This work attempts to present one of the alternatives timely estimation of the unacceptable trend of the company's profitability on the basis of the ongoing (over the year) applied controlling mechanism in order to reverse this situation in a timely manner. Prior to the design of the controlling system itself, it was, on the practical side, intended to conduct a detailed analysis of the current state of planning and management of cut flowers stock. The obtained data were then statistically processed, while the types of the flowers sold in largest quantities, which have the greatest impact on company turnover and affect its profit the most, were determined. The dependencies between buying and selling in individual weeks of the year were derived by the mathematical methods. With regard to sales, turnover and profit data over the 12-month period, weak and strong periods of the year were identified. Finally, on the basis of the previous developments, the expected future development was anticipated and a controlling system was proposed to enable the optimization of the parameters corresponding to the next order.

The processed data were the original data from all the orders and sells of the company during one year. Hence, the results of this study conducted on real data are both valuable and sensitive for this company. Therefore, naturally, its name, as well as the names of its suppliers, were not disclosed in this paper.

Out of the four principal research techniques: study of documents, observations, interviews and questionnaires [4] the first three were employed. The framework of this paper was determined based on the study of the available literature. The observations were made after analysis, selection and evaluation of the collected internal company's documents. Hence, the primary sources of information were obtained through research in the chosen enterprise, whereas the secondary data - through literature research. Both qualitative and quantitative data were gathered.

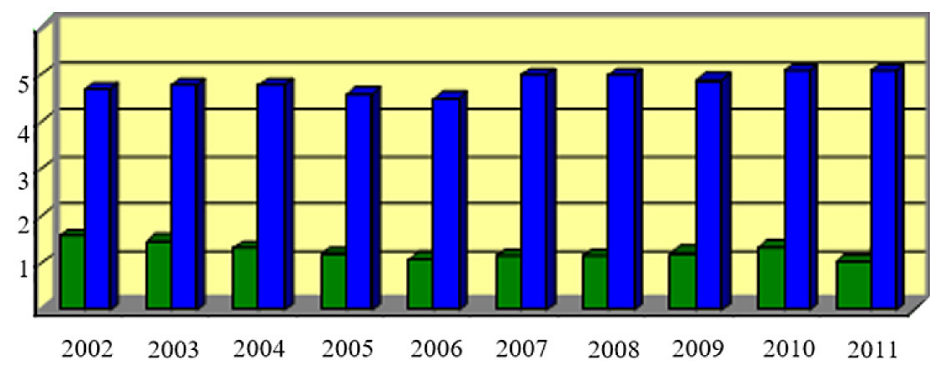

\ Košice $\square$ Bratislava

Fig. 1. Overview of the company's turnover (in millions of euros) for years 2002-2011, comparing the situation in Košice and Bratislava 
In order to understand the current problems in the company, it was necessary to study the company internal materials, reports, and recent statements. Economic analysis is one of the methods utilized in our research. The company uses it, inter alia, for determination of weak, medium and strong periods concerning demand for cut flowers and the associated average rate of rise in selling prices of flowers in comparison with shopping prices. In this paper, the afore-mentioned method was applied together with the analogy method, mainly to determine the trend of profit development in individual weeks during the calendar year and to propose the measures in case of an unfavorable trend of profit development. Statistics and statistical methods had to be exercised since such an analysis required the processing and evaluation of a large amount of collected data. Particularly, the quark method was practiced in statistical sorting. Some calculations were performed by MS Excel, which was also helpful in generating the graphs of character multiplicity distribution, histograms, polygons and tables. The statistical analysis of the obtained data led to prognosis.

At present, the company's managers buy the cut flowers two or three times a week. The total quantity of the ordered flowers is adjusted to the stock current state at the branch and to the unique orders that customers report in advance. The manager's decision about the flowers quantity that should be ordered as well as about its financial amount is therefore difficult. The experience from past years, so-called weekly reporting tables, intuition and handwritten records from a "stronger" sale period may be helpful.

The weekly reports sent to the central processing from the Košice branch at the Bratislava headquarters served to create an overview of the flowers selling and profit from the sale. The reports presented in Table 1 were not compiled in the branch in Košice, but have been established as part of this project. The first column of the table shows the weeks order, the second column the cut flowers sale expressed in purchase prices (excluding VAT), the third column quantifies the percentage profit achieved from the sale of cut flowers in particular week and the last one is the total net sales revenue (excluding VAT) for individual weeks. The red colored values represent the most relevant periods for the company (Valentine's Day, Women's Day, Mother's Day).

The percentage profit from the sale of cut flowers ranged from $20 \%$ to $25 \%$ for most of the year. As can be deduced from Table 1 and Figure 2, in the 41st week of 2011, the percentage of profit from the cut flowers sale fell sharply to about $5 \%$. The reason could be the unscheduled delivery of flowers one or two weeks back and the subsequent discounting below the purchase price.

The table of cut flowers purchase for 2011 was created by processing all the incoming invoices for the stated year, by selecting sale of the best-selling cut flowers as well as the funds spent to buy flowers from individual suppliers. The weeks with strong sales were identified and potential causes (e.g. 6. week - Valentine's Day, 9. week - Women's Day) were analyzed there.

Table 1. Sample processed data relating to the sale of cut flowers for 2011

\begin{tabular}{|c|c|c|c|}
\hline No. & $\begin{array}{c}\text { Sale of cut flowers } \\
\text { (purchase price in euros) }\end{array}$ & $\begin{array}{c}\text { Profit } \\
\text { (in \%) }\end{array}$ & $\begin{array}{c}\text { Overall } \\
\text { (in euros) }\end{array}$ \\
\hline 1 & $10,458.00$ & 19.90 & $12,539.14$ \\
\hline 2 & $10,310.79$ & 15.60 & $11,919.27$ \\
\hline 3 & $12,180.21$ & 19.47 & $14,551.70$ \\
\hline 4 & $10,367.84$ & 19.10 & $12,348.10$ \\
\hline 5 & $9,331.19$ & 16.60 & $10,880.17$ \\
\hline 6 & $18,597.56$ & 20.74 & $22,454.69$ \\
\hline 7 & $13,018.71$ & 18.32 & $15,403.74$ \\
\hline 8 & $11,366.73$ & 21.31 & $13,788.98$ \\
\hline 9 & $18,505.96$ & 20.56 & $22,310.79$ \\
\hline 10 & $15,077.56$ & 21.86 & $18,373.51$ \\
\hline
\end{tabular}

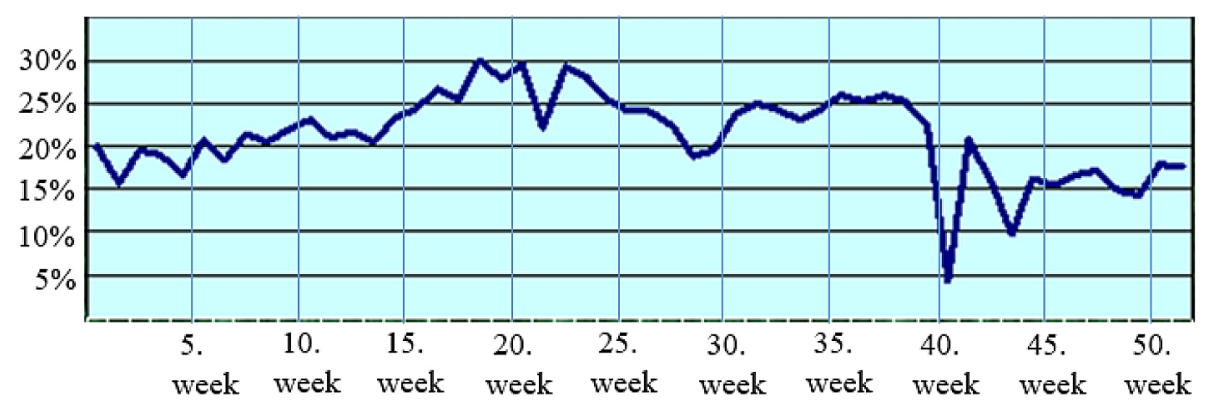

Fig. 2. Percentage profit from sales of cut flowers in the Košice branch of the company for each week of 2011 
The quantities of the most purchased cut flowers were also calculated in pieces for 2011; next, the average weekly sales of individual types of flowers were counted and weeks with demand for individual species of flowers higher by at least $50 \%$ than the general annual average were identified. The variability in the quantity of individual flower purchases was also captured by the graphs expressing purchase of each species of cut flowers, see Fig. 3. Overall, the best-selling plant was the rose. It was sold weekly on an average of 5,625 units, but the sales amplitude reached a value of 11,840 units in one week. The resulting data were table-processed. The company did not handle any form of such table and did not have any similar report until the realization of this work.

\section{RESULTS AND DISCUSSIONS}

Our study identified a missing database as one of the main causes of the company's negative results. There was no processed statistical data within the Košice branch that would transparently monitor the movement of flowers and goods in stock, with purchase and sale categorized by product range. Moreover, even if the headquarters in Bratislava has any statistical indicators, they are not provided for the branch in Košice. As part of the record keeping, only manual records were kept on several "stronger" seasons of flower sales, but they are inadequate. There are no records about the range of cut flowers sold, the weekly balance in stock, likewise the amount of flowers that have been depreciated. The only figure available once a year is the value of the remaining cut flowers from 2010 to the 31 st December 2010 (indication $\mathrm{D}_{0}$ ). The balance of "living" goods in the warehouse adversely affects the profit, as the quality of the flowers diminishes proportionally to the length of the "stay" in the warehouse. This results in a reduction in the selling price. The ideal situation occurs when the cut flowers are sold within three days from the day of delivery to the warehouse. Fresh goods arrive after three days, so the goods that remained in the warehouse from the previous delivery must be discounted. Under unfavorable conditions, the cut flowers can be sold at a lower price than they were bought and in the worst case they become unsellable, thus the whole value of the goods is debited to the company.

The absence of any control system has led to worsening the economic performance, a drop in profit and customer outflows to competition in the company in the past. The company's management decided to quickly resolve the adverse situation and implement a control mechanism to plan and manage the purchase of flowers through assessing the situation at the end of 2011. The proposed solution is to introduce a controlling system that continuously, on a weekly basis, monitors the development of the purchase and sale of cut flowers. Although the controlling system itself is based mainly on a table shown in the Table 2, a number of other spreadsheets, reports and graphs compiled during this project serve to make sales more transparent and as an aid to making the right decisions about the size of orders for specific week. The complete table can be found in [13].

Table 2 allows to closely monitor purchase, sale and clearance sale as well as the continuously reached profit from the sale of cut flowers in the company. In the context of the proposed controlling, the comparison of the realized profit with the expected one indicates the trend of the profit development as well as allows to respond to market needs in a timely manner and to avoid critically low values. All data are the result of invoice, delivery notes and weekly reports processing in the table for 2011.

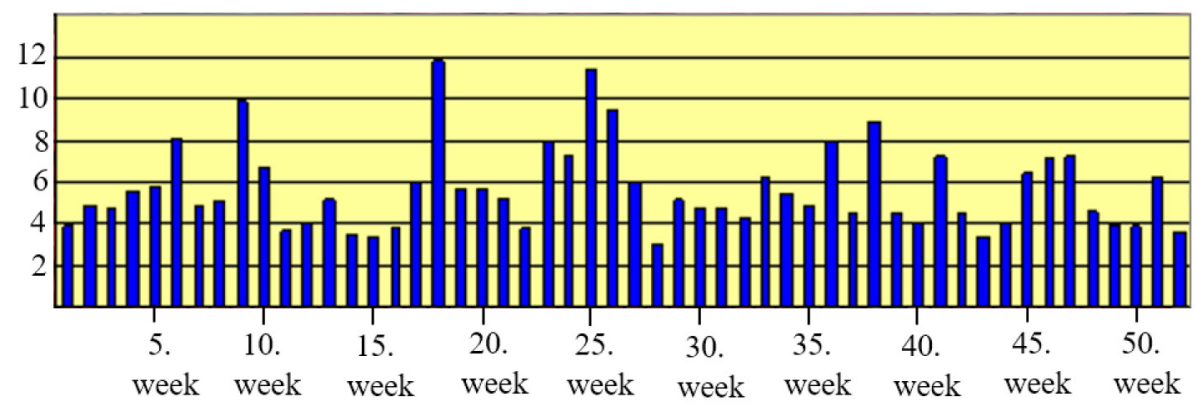

Fig. 3. Purchase of cut roses (in thousands of pieces) in 2011 
Table 2. Controlling system for planning and managing the purchase of flowers

a)

\begin{tabular}{|c|c|c|c|c|c|c|c|c|}
\hline A & $\mathrm{B}[€]$ & $C[€]$ & $\mathrm{D}[€]$ & $E[€]$ & $\mathrm{F}[€]$ & $\mathrm{G}[€]$ & $\mathrm{H}$ & $\mathrm{I}[€]$ \\
\hline \multirow[t]{2}{*}{1} & $2,567.85$ & & 809.60 & $1,434.60$ & $4,812.05$ & & & \\
\hline & $1,350.90$ & 693.70 & & & $2,044.60$ & & & \\
\hline$\Sigma$ & $3,918.75$ & 693.70 & 809.60 & $1,434.60$ & $6,856.65$ & $10,458.00$ & 19.90 & $12,539.14$ \\
\hline \multirow[t]{2}{*}{2} & $3,670.58$ & & 651.29 & $1,087.47$ & $5,409.34$ & & & \\
\hline & $2,916.84$ & 964.41 & & 498.20 & $4,379.45$ & & & \\
\hline$\Sigma$ & $6,587.42$ & 964.41 & 651.29 & $1,585.67$ & $9,788.79$ & $10,310.79$ & 15.60 & $11,919.27$ \\
\hline \multirow[t]{2}{*}{3} & $3,091.17$ & & $1,539.85$ & $2,779.43$ & $7,410.45$ & & & \\
\hline & $3,392.51$ & 876.84 & & 48.80 & $4,318.15$ & & & \\
\hline$\Sigma$ & $6,483.68$ & 876.84 & $1,539.85$ & $2,828.23$ & $11,728.60$ & $12,180.21$ & 19.47 & $14,551.70$ \\
\hline \multirow[t]{2}{*}{4} & $3,477.62$ & & 524.00 & $2,522.28$ & $6,523.90$ & & & \\
\hline & $2,625.34$ & 806.25 & & 35.00 & $3,466.59$ & & & \\
\hline$\Sigma$ & $6,102.96$ & 806.25 & 524.00 & $2,557.28$ & $9,990.49$ & $10,367.84$ & 19.10 & $12,348.10$ \\
\hline \multirow[t]{2}{*}{5} & $3,460.32$ & & 1.079 .45 & $2,261.29$ & $6,801.06$ & & & \\
\hline & $2,897.84$ & 933.90 & & & $3,831.74$ & & & \\
\hline$\Sigma$ & $6,358.16$ & 933.90 & $1,079.45$ & $2,261.29$ & $10,632.80$ & $9,331.19$ & 16.60 & $10,880.17$ \\
\hline \multirow[t]{2}{*}{6} & $2,791.79$ & & $1,289.62$ & $4,581.94$ & $8,663.35$ & & & \\
\hline & $6,418.75$ & $2,628.18$ & & 172.80 & $9,219.73$ & & & \\
\hline$\Sigma$ & $9,201.54$ & $2,628.18$ & $1,289.62$ & $4,754.74$ & $17,883.08$ & $18,597.56$ & 20.74 & $22,454.69$ \\
\hline
\end{tabular}

b)

\begin{tabular}{|c|c|c|c|c|c|c|}
\hline $\mathrm{J}$ & $\mathrm{K}$ & $\mathrm{L}$ & $\mathrm{M}[€]$ & $\mathrm{N}[€]$ & $\mathrm{O}$ & $P$ \\
\hline & & & $7,954.42$ & & & \\
\hline 1 & 1.12 & 1.45 & $4,353.07$ & $2,503.58$ & 1 & \\
\hline 1 & 0.75 & 1.45 & $3,831.07$ & $5,957.72$ & 1 & \\
\hline 2 & 0.86 & 1.35 & $3,379.46$ & $8,349.14$ & 1 & \\
\hline 2 & 0.86 & 1.35 & $3,002.11$ & $6,988.38$ & 1 & \\
\hline 2 & 0.78 & 1.35 & $4,303.72$ & $6,329.08$ & 1 & \\
\hline 2 & 0.73 & 1.35 & $3,589.24$ & $14,293.84$ & 1 & \\
\hline
\end{tabular}

Column A contains weekly reference number of the year to which the data in the concrete row relates. Columns B to E provide an overview of flower purchases from individual suppliers quoted in euros and the frequency of purchases from individual suppliers. From column F it is possible to deduct the total value of flowers purchased in each week of 2011 from all suppliers together. In this column, the weeks when the company expects higher overall sales profit are marked by a darker color. The value in column $\mathrm{F}$ is the total amount in euros that the company spent to buy cut flowers from all suppliers together in the given week. This sum, let us call it $\mathrm{O}_{i}$, consists of 2 components $\mathrm{A}_{\mathrm{i}}$ and $\mathrm{D}_{\mathrm{i}}(1)$.

$$
O_{i}=A_{i}+D_{i}
$$

where: Ai represents the purchase price of flowers that have been bought but also sold in the current week in euros.

$D_{i}$ represents the purchase price of flowers, which have been bought in the current week, but failed to sell, so they remain for clearance sale in euros.

Column $\mathrm{G}$ contains the sum in euros for which the flowers actually sold in the current week were bought. The amount is stated without profit. The value in column $\mathrm{G}$, denoted by $\mathrm{B}_{\mathrm{i}}$, consists of 2 components $\mathrm{A}_{\mathrm{i}}$ and $\mathrm{D}_{\mathrm{i}-1}(2)$.

$$
B_{i}=A_{i}+D_{i-}
$$

$D_{i-1}$ is the purchase price of flowers from the clearance sale from previous week in euros. 
Within the project, a statistical model has been created, based on the real situation, and therefore the assumption that the flowers older than 2 weeks are unmarketable for the warehouse, must go to depreciation. Therefore, the statistical model does not consider the clearance sale of flowers for 3 weeks or more back, because the occurrence of such situations is very rare and thus not statistically significant.

Column $\mathrm{H}$ represents the actual profit from flowers sale in individual weeks, expressed as a percentage. The sales price of flowers sold in particular week is given in column I in euro. This value, denoted $z_{i}$, is given by the relation stated below (3).

$$
z_{i}=A_{i} \cdot c_{i}+D_{i-1} \cdot d_{i}
$$

The average rate of increase in the price of fresh flowers sold in a given week, the purchase price of which was $A_{i}$ is $c_{i}$. The average rate of increase in the price of flowers from the clearance sale sold in the current week, but bought in the previous week for the $D_{i-1}$ price is $d_{i}$.

The type of week depending on the expected profit (desired by company) is marked in column J. In this connection, type 1 means expected high profit in the range $<25 \%, 28 \%$ ) indicated by gray color which is achievable if the value of the purchase price of goods increases by an average of $45 \%$. Type 2 represents the expected moderate profit in the range of $<22 \%, 25 \%$ ) marked with a purple color, which is achievable if the purchase price of goods increases by an average of $35 \%$. The last type 3 is the expected weaker profit in the range of $<19 \%, 22 \%$ ) highlighted in blue, which can be achieved by increasing the purchase price of flowers 1.25 times. The expectations result from the company's strategic plan.

The average rate of increase in the price of flowers compared to the purchase price is expressed in terms of the expected sales profit (column J) at 1.25, 1.35 and 1.45 in column L. Column $\mathrm{K}$ shows the average rate of increase in the purchase price of flowers that were bought last week but failed to sell. They are therefore the flowers from the clearance sale sold in the current week with a lower percentage increase compared to fresh flowers. The information about the size of the clearance sale $\left(D_{i}\right)$ is presented in the column M. Through this argument, it is possible to judge the sufficiency (or shortage) of the flowers for sale to customers until the time when fresh goods will be delivered. Column M contains the amount in euros for which the flowers that were not sold and which remain in the sales status in the next week that were bought in the current week. So far, the company has not been collecting such data over the course of the year and has not consistently monitored the amount of balances for the next week. This figure was known only once a year at the end of the year. This value is indicated by $\mathrm{D}_{0}=7,954.42$ euros. Other values $\mathrm{D}_{\mathrm{i}}, \mathrm{i}>1$ were determined using mathematical relations and MS Excel. Column N, by utilizing mathematical relations filtered, includes the purchase price of flowers that were bought but also sold in the same week. The column $\mathrm{O}$ expresses the degree of marketability of flowers from the clearance sale, which varies throughout the year. It is lower in summer than in winter. The data were consulted with the leader of warehouse. Column P presents the profit development trend expressed by the color scale in pursuance of Table 3. Depending on the color, each week is ranked in one of five levels in relation to the achieved profit.

By choosing the type of week, the manager decides what profit is expected in the particular week. He monitors the situation in previous weeks and verifies his past decisions employing a controlling system table. He is able to see how many flowers (what value in euros) he bought, how much of them he sold with the expected profit and how much he sold in clearance sale in the next week from the data in the table. If the color yellow and ocher occur in the column "Trend", the manager can clearly proclaim that

Table 3. Evaluation of achieved profit

\begin{tabular}{|c|c|c|c|}
\hline \multirow{2}{*}{ Week type - trend } & 1 & 2 & 3 \\
\hline & $\%$ & $\%$ & $\%$ \\
\hline Profit above expectations & $<28,100>$ & $<25,100>$ & $<22,100>$ \\
\hline Expected profit & $<25,28)$ & $<22,25)$ & $<19,22)$ \\
\hline Profit slightly below expectations & $<22,25)$ & $<19,22)$ & $<16,19)$ \\
\hline Profit significantly below expectations & $<19,22)$ & $<16,19)$ & $<13,16)$ \\
\hline Total profit drop noting expectations & $<0,19)$ & $<0,16)$ & $<0,13)$ \\
\hline
\end{tabular}


his previous decisions were wrong. Through the table, he is able to recognize early that the development is negative and it is needed to review the next steps. He can point to the need for lower or higher purchase of cut flowers, to reduce or increase the percentage of increase in the purchase price of flowers.

It is obvious that the fall to so-called red numbers is not some jump, but the result of accumulating mistaken decisions from the past. However, this also applies in reverse. Therefore, it is necessary to monitor the development of profit at least at two-week intervals. While deciding on the size and species composition of the ordered flowers, the reports of the purchased and sold individual species of flowers in the same period in previous years can be helpful. In each week, there is information about how much the company was able to sell to customers. Nevertheless, there is no record whether the purchased quantity was sufficient. Another recommendation for the company was therefore to keep the database of these data, too.

The research that has begun with this work is far from complete. From the four main research phases, i.e. vision, plan, implementation of results in practice and evaluation of utility, the project has just passed the first two and is located in the third one - the test part.

\section{CONCLUSIONS}

In this paper we proposed a tool, the controlling system, which aims at optimizing the orders of a specific company. We agree with [9] that the tool itself does not lead to improvements per se. The practical use of the tool bridges the gap between theoretical work and practice, and moves one step towards a better cooperation with the suppliers.

The first and most important advantage of the offered controlling system for the company is the suggested way of data processing and data archiving and next registering the purchase and sale of cut flowers, which form almost $68 \%$ of the company's turnover. First of all, it gives the information on how often to track the data, what data to track as well as how to collect and organize them. What is even more important it gives the information on how to subsequently identify the trends in profit development from them. By monitoring trends results, i.e. the color scale (from dark blue through green, yellow, ocher to red color), the manager reveals the accuracy of his previous decisions, favorable or unfavorable profit development that was expected by the company in a given week. The area of yellow and ocher color highlights the need for change. This may be an increase / decrease in the purchase of cut flowers, or a reassessment of the particular week's inclusion into another type of week. Updating the table of the controlling system is quite simple, but requires regular recording the required data (on a weekly basis). It serves as a guide in deciding what quantity of goods to order for next week to meet customers' requirements.

In the process of creating the main table of the controlling system, a series of extra reports and graphs emerged that ultimately lead to sales clarity. What is more, they serve as a means of appropriate deciding on the size of the orders for certain week.

The table of the controlling system for planning and managing purchases would have a much higher informative value if the records had been processed in a few years back. It would be possible to compare year-on-year average profits, trends, value of purchases increased by valorization and, last but not least, what kind of cut flowers the consumers preferred in specific week plus in what quantity.

The lack of a controlling system is tantamount to the impossibility to estimate the response of customers in a given week. However, this is a variable that cannot be calculated by any system. Although each statistical system of the data in its evaluation has to be measured with a high degree of randomness (especially if it relates to customer behavior), the comparison of statistical data itself over the same period during several consecutive years has its noticeable value. According to the statement of the warehouse manager (testing runs since October 2012), the collected data for 2011 are a great help when ordering the goods. Another great help for the company is the designed table of "Best-selling cut flowers for 2011", where the purchase of roses, carnations, chrysanthemums, anthuriums, gerberas and lilies is calculated in weeks. Even in this case, the processing of several years back gives the company even more relevant information about the quantity of individual types of best-selling cut flowers, thus giving the possibility of year-to-year comparison. In the testing process, there also occurred a need to capture the sale of the individual species and thus to complete the circulation of the purchased species of the best-selling cut flowers. 
From the practical point of view, the first test results of the proposed controlling system show that it is a suitable tool for continuously tracking profit trends from flower sales as it can greatly eliminate the current uncertainty in order size decision making, control the balance of cut flowers in the warehouse, track the sales trend on a weekly basis and allows for timeliness in the event of adverse sales developments.

The results of this study were given to the representatives of the company for implementation in the test phase. After one year, the results will be compared and if appropriate, some changes will be suggested. Although the final controlling system should be well-made only afterwards, the conclusions of this study as well as pretreatment of the data and their analysis have already been highly evaluated by the representatives of the company. This fact underlines the importance of the presented work.

\section{Acknowledgements}

This work was supported by the Slovak Research and Development Agency under the contract No. APVV-14-0892 and by the grant VEGA $1 / 0437 / 17$.

\section{REFERENCES}

1. Aksoy A. and N. Öztürk, Supplier selection and performance evaluation in just-in-time production environments, Expert Systems with Applications 38(5), 2011, 6351-6359.

2. Araz C. and I. Ozkarahan, Supplier evaluation and management system for strategic sourcing based on a new multicriteria sorting procedure, International Journal of Production Economics 106(2), 2007, 585-606.

3. Ballou R.H., Business logistics/supply chain management: planning, organizing, and controlling the supply chain. Pearson Education India, 2007.

4. Bryman A., Social Research Methods. Oxford University Press, 2012.
5. Cebi F. and D. Bayraktar, An integrated approach for supplier selection, Logistics Information Management 16(6), 2003, 395-400.

6. Dou Y., Q. Zhu and J. Sarkis, Evaluating green supplier development programs with a grey-analytical network process-based methodology, European Journal of Operational Research, 233(2), 2013, 420-431.

7. Fahy J., A resource-based analysis of sustainable competitive advantage in a global environment, International Business Review 11(1), 2002, 57-77.

8. Foss T., The integration of control systems for the supply chain and transportation domains, Proceedings of the 12th World Conference on Transport Research (WCTR), July 2010, 1-25.

9. Imeri S., K. Shahzad, J. Takala, Y. Liu, I. Sillanpää and T. Ali, Evaluation and selection process of suppliers through analytical framework: an empirical evidence of evaluation tool, Management and Production Engineering Review 6(3), 2015, 10-20.

10. Khouri S., Analysis of information as the content of an enterprise information system, Journal of Engineering Annals of Faculty of Engineering Hunedoara 7(2), 2009, 205-208.

11. Lambert D.M., J.S. Stock and L.M. Ellram, Logistics. Computer Press, 2000.

12. Otto A. and H. Kotzab, Does supply chain management really pay? Six perspectives to measure the performance of managing a supply chain, European Journal of Operational Research 144(2), 2003, 306-320.

13. Plačintárová H., Controlling as a tool of lean logistics under buying flowers. Master thesis, 2013.

14. Rushton A., P. Croucher and P. Baker, The handbook of logistics and distribution management: understanding the supply chain. Kogan Page Publishers, 2014.

15. Thakkar J., A. Kanda and S.G. Deshmukh, Supply chain management in SMEs: development of constructs and propositions, Asia Pacific Journal of Marketing and Logistics 20(1), 2008, 97-131.

16. Ždímalová M., Z. Krivá and T. Bohumel, Graph cuts in image processing, APLIMAT 2015, 14th Conference on Applied Mathematics, Institute of Mathematics and Physics, Faculty of Mechanical Engineering, STU in Bratislava, 2015, 774-786. 